\title{
The comparison of effects of balneotherapy, water-based and land-based exercises on disease activity, symptoms, sleep quality, quality of life and serum sclerostin level in patients with ankylosing spondylitis: A prospective, randomized study
}

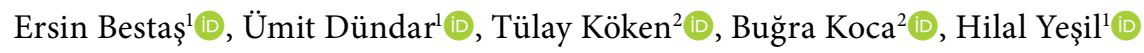 \\ ${ }^{1}$ Department of Physical Medicine and Rehabilitation, Afyonkarahisar Health Sciences University, Afyon, Türkiye \\ ${ }^{2}$ Clinical Biochemistry, Afyonkarahisar Health Sciences University, Afyon, Türkiye
}

\begin{abstract}
Objectives: This study aims to compare the effects of balneotherapy, water-based exercise (WBE), and land-based exercise (LBE) on disease activity, symptoms, sleep quality, quality of life, and serum sclerostin level (SSL) in patients with ankylosing spondylitis (AS).

Patients and methods: Between January 2019 and January 2020, a total of 60 patients ( 35 males, 25 females; mean age: $40.9 \pm 11.2$ years; range, 18 to 55 years) who were diagnosed with AS were randomly divided into the balneotherapy $(n=20)$, WBE $(n=20)$, and LBE ( $n=20)$ groups (20 sessions of treatment in groups of five to six patients). The patients were evaluated before treatment and at 4 and 12 weeks using the Bath Ankylosing Spondylitis Disease Activity Index (BASDAI), Bath Ankylosing Spondylitis Functional Index (BASFI), Bath Ankylosing Spondylitis Metrology Index (BASMI), Ankylosing Spondylitis Disease Activity Score-C-reactive protein (ASDAS-CRP), Maastricht Ankylosing Spondylitis Enthesitis Score (MASES), Ankylosing Spondylitis Quality of Life (ASQoL) Scale, Fatigue Severity Scale (FSS), and Pittsburg Sleep Quality Index (PSQI), and SSL were measured.
\end{abstract}

Results: Statistically significant improvements in the BASDAI, BASFI, MASES, BASMI, ASQoL, FSS, and ASDAS-CRP scores were observed in all groups at 4 and 12 weeks of follow-up $(p<0.05)$. A significant improvement in sleep latency was seen in the balneotherapy and WBE groups. Changes in SSL were not statistically significant in any group $(p>0.05)$.

Conclusion: Balneotherapy, WBE, and LBE are effective in the treatment of AS, and the beneficial effects may last for at least 12 weeks.

Keywords: Exercise, quality of life, sclerostin, sleep quality, spondyloarthritis.

Ankylosing spondylitis (AS) is an inflammatory rheumatic disease that causes structural and functional impairments such as impaired quality of life (QoL), decreased spinal movements, and axial deformity. ${ }^{1-3}$ A combination of pharmacological and non-pharmacological treatments is recommended as an ideal approach in the management of AS. ${ }^{3}$ In recent years, dramatic advances have been made in the pharmacological treatment of AS with the discovery and widespread use of biological agents. ${ }^{4}$ Nevertheless, non-pharmacological approaches such as education, exercise, and physical therapy continue to be an essential part of AS treatment. ${ }^{5}$

Current evidence demonstrates the effectiveness of exercise in AS. ${ }^{6}$ Exercise can be performed in the form of a home program, as supervised group

Received: June 01, 2021 Accepted: September 27, 2021 Published online: December 24, 2021

Correspondence: Hilal Yeşil, MD. Afyonkarahisar Sağlık Bilimleri Üniversitesi, Fiziksel Tıp ve Rehabilitasyon Anabilim Dalı, 03030 Afyonkarahisar, Türkiye. Tel: +90 505 - 4423141 e-mail: dradanur@yahoo.com

\section{Citation:}

Bestaş E, Dündar Ü, Köken T, Koca B, Yeșil H. The comparison of effects of balneotherapy, water-based and land-based exercises on disease activity, symptoms, sleep quality, quality of life and serum sclerostin level in patients with ankylosing spondylitis: A prospective, randomized study. Arch Rheumatol 2022;37(2):159-168. 
exercise, or as a water-based exercise (WBE) program. ${ }^{7}$ However, there is still no consensus regarding the exercise method and exercise parameters that provide the greatest clinical benefit. In addition to exercise, balneotherapy has analgesic and myorelaxant effects and can also be an important non-pharmacological treatment option for AS patients with pain and paraspinal muscle contractures. ${ }^{8}$ Significant improvements in disease activity and functional parameters have been reported in AS patients following balneotherapy. 7,9

In recent years, it has been reported that the canonical Wnt/ $\beta$-catenin signaling pathway plays a key role in the development of AS through bone morphogenesis and homeostasis. ${ }^{10}$ Dickkopf-1 (dkk-1) and sclerostin are canonical Wnt/ $\beta$-catenin signaling pathway inhibitors. ${ }^{11}$ Ankylosing spondylitis patients have significantly lower serum sclerostin levels (SSLs) compared to healthy controls, and low SSLs have been associated with new syndesmophyte formation and radiographic progression. ${ }^{12}$ To the best of our knowledge, there is no study in the literature evaluating the effect of exercise on SSLs in AS patients.

In the present study, we aimed to compare the effects of balneotherapy, WBE, and land-based exercise (LBE) on disease activity, symptoms, sleep quality, QoL, and SSL in patients with AS.

\section{PATIENTS AND METHODS}

This single-center, prospective, randomized study was conducted at Afyonkarahisar Health Sciences University, Department of Physical Medicine and Rehabilitation between January 2019 and January 2020. A total of 60 patients (35 males, 25 females; mean age: 40.9 \pm 11.2 years; range, 18 to 55 years) who were followed in our clinic were included (Figure 1). Inclusion criteria were as follows: having a diagnosis of AS according to the modified New York diagnostic criteria and sedentariness (no physical activity for at least three days a week within the last

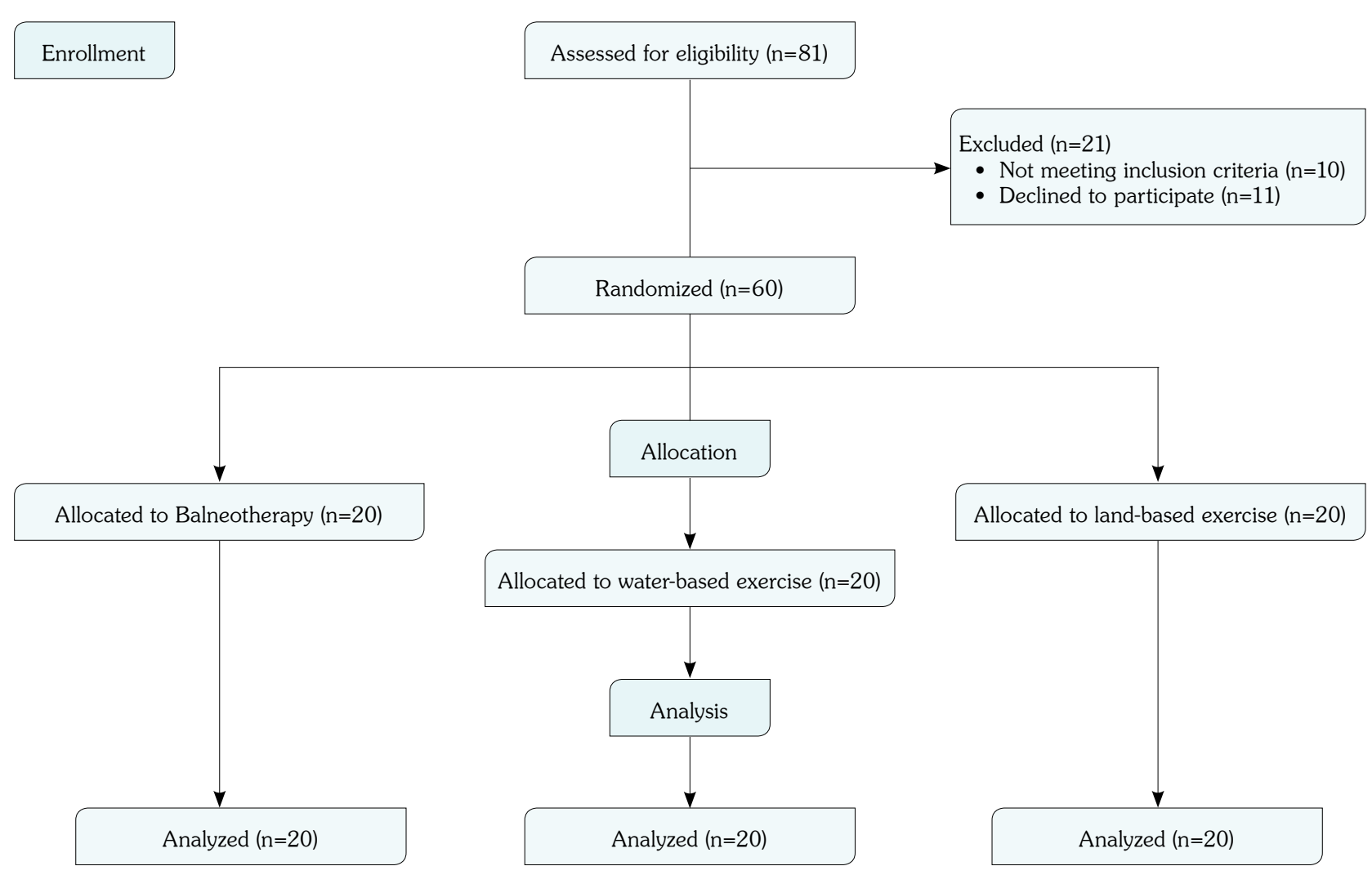

Figure 1. Study flow chart. 
three months). Exclusion criteria included the presence of any of the following: any orthopedic, neurological, or mental illness that may interfere with exercise; use of an assistive device for ambulation; orthopedic joint prosthesis; total spinal ankylosis; lesions that disrupt skin integrity; uncontrolled cardiopulmonary disease (such as hypertension, chronic obstructive pulmonary disease, heart failure); pregnancy; history of malignancy or recent surgical procedure; regular balneotherapy within the previous three months, and active peripheral arthritis. The patients continued their regular medication with no dosage changes, and no new medications were initiated during the study period.

\section{Randomization and blinding}

Patients with AS who met the inclusion criteria and consented to participate were randomized into three treatment groups using a numbered envelope method. The first group $(n=20)$ received balneotherapy, the second group $(n=20)$ received WBE therapy, and the third group $(n=20)$ received LBE therapy. Investigators, and analysts were blinded, with the exception of patients.

\section{Interventions}

All of the interventions lasted for four weeks and consisted of a total of 20 sessions held five days a week in groups of five to six patients.

The balneotherapy group received a total of 20 min of treatment per session in the form of a whole-body bath in a spa pool at $39^{\circ} \mathrm{C}$. The composition of the spa water included cations, with the highest concentrations of sodium (1,394 $\mathrm{mg} / \mathrm{L})$, calcium (156 mg/L), and potassium (117 mg/L), and anions, the most predominant being chloride $(1,871 \mathrm{mg} / \mathrm{L})$, bicarbonate $(1,012 \mathrm{mg} / \mathrm{L})$, and sulfate $(579 \mathrm{mg} / \mathrm{L})$.

The WBE group performed a total of $60 \mathrm{~min}$ of in-pool exercise per session in a swimming pool at 32 to $33^{\circ} \mathrm{C}$, accompanied by a physiotherapist. The sessions were organized as a 15-min warm-up (e.g., walking forward and backward), followed by $40 \mathrm{~min}$ of aerobic exercises (e.g., jumping), active range of motion exercises for all extremities, strengthening exercises, straight stance (upright posture) exercise, breathing exercises, and relaxation exercises (lying on the back), and ending with a 5-min cool-down (e.g., slow walking, squatting).
The LBE group also received a total of 60 min of therapy under the supervision of a physiotherapist. The exercise program was organized as 5 min of muscle relaxation exercises (e.g., deep breathing, stretching, relaxation of different muscle groups, lying in supine position); 25 min of cervical, thoracic, and lumbar spine flexibility exercises (e.g., flexion and extension) and stretching of major muscle groups (abdominal muscles, erector spina, hamstring, quadriceps, hip flexors, knee muscles, and stretching of the neck, trunk, and all extremities); and 10 min of straight posture exercise, breathing exercises, and muscle strengthening exercises (e.g., upper and lower extremity strengthening exercises, isometric exercises for superficial trunk muscles). Finally, therapeutic local massage was applied to the paravertebral muscles for $20 \mathrm{~min}$.

No adverse events were observed related to the exercises or balneotherapy.

\section{Outcomes}

The patients were evaluated before the intervention, at four weeks (at the end of the intervention), and at 12 weeks after initial examination. Demographic data (age, sex, education, body mass index) and clinical data (age at AS diagnosis, disease duration, medications used, and smoking and alcohol use) were obtained from patient files and through face-to-face interviews. Assessments included the Bath Ankylosing Spondylitis Disease Activity Index (BASDAI), Bath Ankylosing Spondylitis Functional Index (BASFI), Bath Ankylosing Spondylitis Metrology Index (BASMI), Ankylosing Spondylitis Disease Activity Score-C-reactive protein (ASDAS-CRP), Maastricht Ankylosing Spondylitis Enthesitis Score (MASES), Ankylosing Spondylitis Quality of Life (ASQoL) Scale, Fatigue Severity Scale (FSS), Pittsburg Sleep Quality Index (PSQI), and measurements of chest expansion and SSL.

BASDAI: This instrument consists of six questions assessing the patient's fatigue, spinal pain, joint pain/swelling, areas of localized tenderness, pain severity, and duration of morning stiffness in the last week. Higher scores indicate increased disease activity, while scores of $\geq 4$ indicate higher disease activity. ${ }^{13}$

BASFI: This 10-item scale evaluates the degree of functional limitation of AS patients in activities 
of daily living. All items are evaluated by the patient using a Visual Analog Scale (VAS). Higher scores indicate more severe impairment. ${ }^{14}$

BASMI: Mobility of the cervical, thoracic, and lumbar regions are assessed using five measurements: modified Schober's test, tragus-wall distance, cervical rotation, lumbar lateral flexion, and intermalleolar distance measurements. The scores from these measurements are summed, with lower scores reflecting better spinal movement. ${ }^{15}$

MASES: Enthesitis in AS is assessed by palpating the locations specified in the MASES to determine their sensitivity. ${ }^{16}$

Chest expansion measurement: Chest circumference is measured at the level of the fourth intercostal space during forced expirium and inspirium. ${ }^{17}$

ASQoL: This instrument consists of 18 questions answered by the patient as yes (1 point) or no (0 points), depending on the patient's current condition. Higher scores indicate poorer QoL. ${ }^{18}$

FSS: This nine-item scale evaluates the effect of fatigue on functionality. Scores of $\geq 4$ indicate severe fatigue. ${ }^{19}$

PSQI: This subjective self-report instrument consists of seven subscales evaluating sleep activity, sleep duration, use of sleep medication, daytime dysfunction, sleep latency, sleep quality, and sleep disturbance in the last month. Individuals with a total score between 0 and 4 have good sleep quality, and those between 5 and 21 have poor sleep quality. ${ }^{20}$

ASDAS-CRP: This composite index combines BASDAI items 2, 3, and 6 with CRP value. Values over 3.5 indicate very high disease activity, while values below 1.3 are considered inactive disease. ${ }^{21}$

SSL: Serum sclerostin concentrations (ng/mL) were measured using a human sclerostin enzyme-linked immunosorbent assay (ELISA) kit (SunRed Biological Technology, Shanghai, PRC) read with a ChemWell 2910 automated ELISA analyzer (Awareness Technology Inc., Palm City, FL, USA).

\section{Statistical analysis}

Statistical analysis was performed using the SPSS version 18.0 (SPSS Inc., Chicago, IL, USA) and MedCalc version 13.0 (Medcalc Software, Ostend, Belgium) software. Continuous variables were expressed in mean \pm standard deviation (SD), while categorical variables were expressed in number and frequency. The Kolmogorov-Smirnov test was conducted for normally-distributed numerical

Table 1. Baseline demographic and clinical characteristics of the patients

\begin{tabular}{|c|c|c|c|c|c|c|c|}
\hline & \multicolumn{2}{|c|}{ Balneotherapy $(\mathrm{n}=20)$} & \multicolumn{2}{|c|}{ WBE $(n=20)$} & \multicolumn{2}{|c|}{$\operatorname{LBE}(n=20)$} & \multirow[b]{2}{*}{$p$} \\
\hline & $\mathrm{n}$ & Mean \pm SD & $\mathrm{n}$ & Mean \pm SD & $\mathrm{n}$ & Mean \pm SD & \\
\hline Age (year) & & $42.3 \pm 9.0$ & & $42.0 \pm 12.3$ & & $38.6 \pm 12.2$ & 0.644 \\
\hline $\begin{array}{l}\text { Sex } \\
\text { Female } \\
\text { Male }\end{array}$ & $\begin{array}{c}7 \\
13\end{array}$ & & $\begin{array}{l}10 \\
10\end{array}$ & & $\begin{array}{c}8 \\
12\end{array}$ & & 0.619 \\
\hline Body mass index $\left(\mathrm{kg} / \mathrm{m}^{2}\right)$ & & $30.9 \pm 5.5$ & & $27.7 \pm 3.7$ & & $28.5 \pm 4.3$ & 0.104 \\
\hline Age at initial diagnosis (year) & & $35.6 \pm 8.5$ & & $33.9 \pm 10.6$ & & $30.3 \pm 9.1$ & 0.229 \\
\hline Symptom duration (month) & & $81.7 \pm 95.8$ & & $84.1 \pm 79.3$ & & $99.9 \pm 88.2$ & 0.527 \\
\hline $\begin{array}{l}\text { Education levels } \\
\text { Illiterate/Primary/Secondary/High/University }\end{array}$ & $1 / 7 / 3 / 5 / 4$ & & $0 / 8 / 1 / 9 / 2$ & & $2 / 7 / 3 / 3 / 5$ & & 0.453 \\
\hline $\begin{array}{l}\text { Drugs } \\
\text { NSAID } \\
\text { Biologic agents } \\
\text { NSAID and sulfasalazine } \\
\text { Biologic agents and NSAID }\end{array}$ & $\begin{array}{l}7 \\
6 \\
5 \\
2\end{array}$ & & $\begin{array}{l}4 \\
5 \\
7 \\
4\end{array}$ & & $\begin{array}{l}8 \\
3 \\
7 \\
2\end{array}$ & & 0.705 \\
\hline Alcohol (yes) & 2 & & 0 & & 2 & & 0.343 \\
\hline Smoking (yes) & 4 & & 8 & & 4 & & 0.256 \\
\hline
\end{tabular}


variables. The Pearson chi-square test was used for comparisons of categorical data, KruskalWallis test for comparisons of quantitative variables, and analysis of variance (ANOVA) for within-group comparisons of repeated measures. In case of significant results in Kruskal-Wallis test and repeated measures ANOVA, post-hoc analysis was performed using the Dunn's test and least significant difference (LSD) test, respectively. A $p$ value of $<0.05$ was considered statistically significant.

\section{RESULTS}

There were no significant differences in demographic or clinical characteristics among the groups (Table 1).

Comparison of BASDAI, BASFI, BASMI, MASES, and ASQoL values obtained before treatment and at 4 and 12 weeks of follow-up showed statistically significant improvements in all variables in all treatment groups $(p<0.001)$, with no significant differences among the groups at 4 or 12 weeks ( $>0.05)$ (Table 2). The WBE group showed a statistically significant improvement in chest expansion at 4- and 12-week follow-up $(p<0.05)$ (Table 2).

When the FSS values were compared between the pre-treatment period and 4 and 12 weeks of follow-up, a statistically significant improvement in FSS was observed in all groups $(p<0.001)$, with a significantly greater improvement in the LBE group at four weeks $(p=0.018)$ (Table 2). There was also statistically significant improvement in total PSQI scores in all groups at 4 and 12 weeks of follow-up compared to pre-treatment scores $(p<0.001)$. The balneotherapy and WBE groups showed a significant improvement in sleep latency, while sleep duration improved significantly only in the LBE group (Table 2).

Evaluation of ASDAS-CRP showed that all treatment groups had significant improvement over pre-treatment values at 4 and 12 weeks of follow-up ( $p<0.001)$. At Week 4 , the LBE group had significantly greater improvement compared to the other groups $(p=0.022)$, while at Week 12 , the balneotherapy and LBE groups showed a significantly greater improvement in ASDAS-CRP compared to the WBE group $(\mathrm{p}=0.001)$ (Table 3$)$.

\begin{tabular}{|c|c|c|c|c|}
\hline & Balneotherapy & WBE & LBE & \\
\hline & Mean \pm SD & Mean \pm SD & Mean \pm SD & $p$ \\
\hline \multicolumn{5}{|l|}{ BASDAI } \\
\hline Baseline & $4.9 \pm 1.5$ & $5.0 \pm 1.6$ & $4.7 \pm 1.6$ & 0.984 \\
\hline 4 weeks & $2.5 \pm 1.4^{*}$ & $2.6 \pm 1.6^{\prime \prime}$ & $1.7 \pm 1.2^{*}$ & 0.133 \\
\hline 12 weeks & $2.4 \pm 1.3^{*}$ & $3.0 \pm 1.5^{*}$ & $2.1 \pm 1.4^{*}$ & 0.099 \\
\hline \multicolumn{5}{|l|}{ BASFI } \\
\hline Baseline & $3.2 \pm 1.5$ & $3.8 \pm 1.5$ & $3.4 \pm 1.8$ & 0.432 \\
\hline 4 weeks & $1.7 \pm 1.1^{*}$ & $1.9 \pm 1.5^{\mathrm{m}}$ & $1.1 \pm 0.8^{*}$ & 0.061 \\
\hline 12 weeks & $1.4 \pm 1.0^{*}$ & $1.9 \pm 1.2^{\mathrm{s}}$ & $1.3 \pm 1.0^{* \prime}$ & 0.218 \\
\hline \multicolumn{5}{|l|}{ BASMI } \\
\hline Baseline & $2.3 \pm 1.3$ & $2.8 \pm 0.9$ & $2.8 \pm 1.6$ & 0.349 \\
\hline 4 weeks & $1.9 \pm 1.2^{*}$ & $2.1 \pm 0.9^{*}$ & $2.3 \pm 1.5^{*}$ & 0.636 \\
\hline 12 weeks & $1.8 \pm 1.3^{*}$ & $2.1 \pm 0.9^{*}$ & $2.3 \pm 1.6^{*}$ & 0.410 \\
\hline \multicolumn{5}{|l|}{ MASES } \\
\hline Baseline & $3.2 \pm 2.7$ & $4.6 \pm 3.4$ & $3.3 \pm 2.7$ & 0.336 \\
\hline 4 weeks & $1.6 \pm 1.9^{*}$ & $1.8 \pm 2.5^{*}$ & $1.1 \pm 1.5^{*}$ & 0.649 \\
\hline 12 weeks & $1.4 \pm 1.7^{*}$ & $1.7 \pm 1.6^{*}$ & $1.2 \pm 1.8^{*}$ & 0.328 \\
\hline \multicolumn{5}{|c|}{ Chest expansion } \\
\hline Baseline & $4.6 \pm 1.7$ & $4.6 \pm 1.4$ & $4.5 \pm 1.8$ & 0.983 \\
\hline 4 weeks & $4.9 \pm 2.0$ & $5.5 \pm 1.7^{*}$ & $4.9 \pm 1.9$ & 0.393 \\
\hline 12 weeks & $4.9 \pm 2.0$ & $5.2 \pm 1.7^{*}$ & $5 \pm 2.4$ & 0.757 \\
\hline \multicolumn{5}{|l|}{ ASQoL } \\
\hline Baseline & $10.8 \pm 3.33$ & $12.5 \pm 3.8$ & $11.1 \pm 4.5$ & 0.464 \\
\hline 4 weeks & $4.5 \pm 2.6^{*}$ & $6.9 \pm 4.8^{*}$ & $3.8 \pm 2.8^{*}$ & 0.085 \\
\hline 12 weeks & $4.8 \pm 2.8^{*}$ & $7.0 \pm 4.4^{*}$ & $4.4 \pm 3.7^{*}$ & 0.105 \\
\hline \multicolumn{5}{|l|}{ FSS } \\
\hline Baseline & $4.6 \pm 1.4$ & $4.8 \pm 1.1$ & $4.3 \pm 1.3$ & 0.587 \\
\hline 4 weeks & $3.1 \pm 1.3^{*}$ & $3.5 \pm 1.5^{n}$ & $2.3 \pm 0.9^{*}$ & $0.018^{* * *}$ \\
\hline 12 weeks & $2.9 \pm 1.2^{*}$ & $3.2 \pm 1.1^{*}$ & $2.5 \pm 1.2^{*}$ & 0.108 \\
\hline \multicolumn{5}{|l|}{ PSQI-SSQ } \\
\hline Baseline & $1.3 \pm 0.6$ & $1.3 \pm 0.5$ & $1.6 \pm 0.9$ & 0.381 \\
\hline 4 weeks & $0.7 \pm 0.6^{*}$ & $0.9 \pm 0.6^{*}$ & $0.7 \pm 0.6^{*}$ & 0.412 \\
\hline 12 weeks & $1.0 \pm 0.5^{*}$ & $0.9 \pm 0.3^{\prime \prime}$ & $0.8 \pm 0.7^{*}$ & 0.599 \\
\hline \multicolumn{5}{|c|}{ PSQI-sleep latency } \\
\hline Baseline & $1.3 \pm 1.0$ & $1.7 \pm 0.9$ & $1.5 \pm 1.5$ & 0.541 \\
\hline 4 weeks & $0.7 \pm 0.8^{*}$ & $0.8 \pm 0.7^{*}$ & $1.2 \pm 1.2$ & 0.504 \\
\hline 12 weeks & $0.7 \pm 0.8^{*}$ & $1.1 \pm 0.8^{*}$ & $1.3 \pm 1.0$ & 0.061 \\
\hline \multicolumn{5}{|l|}{ PSQI-SDR } \\
\hline Baseline & $1.2 \pm 0.8$ & $1.0 \pm 1.0$ & $1.4 \pm 1.2$ & 0.380 \\
\hline 4 weeks & $0.9 \pm 0.7$ & $0.7 \pm 0.8$ & $0.5 \pm 0.8^{*}$ & 0.224 \\
\hline 12 weeks & $0.8 \pm 0.8$ & $0.5 \pm 0.6$ & $0.7 \pm 1.0^{*}$ & 0.571 \\
\hline \multicolumn{5}{|l|}{ PSQI-HSE } \\
\hline Baseline & $0.3 \pm 0.6$ & $0.8 \pm 1.1$ & $1.1 \pm 1.4$ & 0.176 \\
\hline 4 weeks & $0.3 \pm 0.4^{*}$ & $0.3 \pm 0.8^{*}$ & $0.2 \pm 0.4^{*}$ & 0.832 \\
\hline 12 weeks & $0.1 \pm 0.2^{\prime \prime}$ & $0.2 \pm 0.9^{\prime \prime}$ & $0.6 \pm 1.0^{*}$ & 0.059 \\
\hline PSQI-SD & & & & \\
\hline Baseline & $1.6 \pm 0.5$ & $2.0 \pm 0.6$ & $1.7 \pm 0.6$ & 0.167 \\
\hline 4 weeks & $1.2 \pm 0.5^{*}$ & $1.2 \pm 0.4^{*}$ & $1.3 \pm 1.0^{*}$ & 0.930 \\
\hline 12 weeks & $1.1 \pm 0.7^{*}$ & $1.3 \pm 0.5^{\prime \prime}$ & $1.3 \pm 0.4^{*}$ & 0.394 \\
\hline PSQI-UOSM & & & & \\
\hline Baseline & $1.6 \pm 0.5$ & $2.0 \pm 0.6$ & $1.7 \pm 0.57$ & 0.167 \\
\hline 4 weeks & $1.2 \pm 0.5^{*}$ & $1.2 \pm 0.4^{*}$ & $1.3 \pm 1.0^{*}$ & 0.930 \\
\hline 12 weeks & $1.1 \pm 0.7^{*}$ & $1.3 \pm 0.5^{\prime \prime}$ & $1.3 \pm 0.4^{*}$ & 0.394 \\
\hline PSQI-DD & & & & \\
\hline Baseline & $1.6 \pm 1.0$ & $1.6 \pm 1.1$ & $1.3 \pm 1.2$ & 0.557 \\
\hline 4 weeks & $0.9 \pm 1.0^{*}$ & $0.9 \pm 0.9^{*}$ & $0.4 \pm 0.6^{*}$ & 0.248 \\
\hline 12 weeks & $0.7 \pm 0.9^{*}$ & $0.8 \pm 0.7^{* \prime}$ & $0.5 \pm 0.6^{*}$ & 0.392 \\
\hline PSQI total sc & & & & \\
\hline Baseline & $7.3 \pm 2.4$ & $8.2 \pm 3.0$ & $8.5 \pm 5.2$ & 0.611 \\
\hline 4 weeks & $4.6 \pm 2.5^{*}$ & $4.8 \pm 3.1^{*}$ & $4.1 \pm 2.9^{*}$ & 0.686 \\
\hline 12 weeks & $4.2 \pm 2.7^{*}$ & $4.8 \pm 2.1^{*}$ & $5 \pm 3.6^{*}$ & 0.494 \\
\hline ASDAS-CRP & & & & \\
\hline Baseline & $2.8 \pm 0.6$ & $3.1 \pm 0.8$ & $2.8 \pm 0.8$ & 0.352 \\
\hline 4 weeks & $1.8 \pm 0.5^{*}$ & $2.1 \pm 0.8^{\prime \prime}$ & $1.5 \pm 0.6^{*}$ & $0.022^{* * *}$ \\
\hline 12 weeks & $1.8 \pm 0.5^{*}$ & $2.3 \pm 0.5^{*}$ & $1.7 \pm 0.7^{*}$ & $0.001^{* *}$ \\
\hline Sclerostin (n & & & & \\
\hline Baseline & $6.9 \pm 2.6$ & $9.1 \pm 5.4$ & $7.5 \pm 2.6$ & 0.505 \\
\hline 4 weeks & $6.5 \pm 2.7$ & $8.3 \pm 5.1$ & $8.0 \pm 3.3$ & 0.421 \\
\hline 12 weeks & $7.4 \pm 2.6$ & $9.5 \pm 6.7$ & $8.0 \pm 3.8$ & 0.743 \\
\hline $\begin{array}{l}\text { ASDAS-CRP: } \\
\text { Water-based } \\
\text { Disease Activ } \\
\text { Bath Ankylosi } \\
\text { Enthesitis Sco } \\
\text { Scale; PSQI: P } \\
\text { efficiency; SD: } \\
\text { Daytime dysfu } \\
\text { group compar }\end{array}$ & $\begin{array}{l}\text { ng Spondylitis Dis } \\
\text { BE: Land-based } \\
\text { BASFI: Bath An } \\
\text { ylitis Metrology Ind } \\
\text { : Ankylosing Spond } \\
\text { eep Quality Index; }\end{array}$ & $\begin{array}{l}\text { se Activity S } \\
\text { rcise; BASDA } \\
\text { losing Spondy } \\
\text { x; MASES: Ma } \\
\text { litis Quality of } \\
\text { Q: Subjective s } \\
\text { duration; UOS } \\
\text { on statistically } \\
\text {.05). }\end{array}$ & $\begin{array}{l}\text { re-C-reactive } \\
\text { Bath Ankylosi } \\
\text { S Functional } 1 \\
\text { tricht Ankylos } \\
\text { Scale; FSS: F } \\
\text { p quality; HSE } \\
\text { Use of sleep n } \\
\text { nificant ( } \mathrm{p}<0.0\end{array}$ & $\begin{array}{l}\text { tein; WBE } \\
\text { Spondylitis } \\
\text { ex; BASMI } \\
\text { Spondylitis } \\
\text { sue Severity } \\
\text { abitual sleep } \\
\text { ication; DD } \\
* \text { *atween }\end{array}$ \\
\hline
\end{tabular}




\begin{tabular}{|c|c|c|c|c|}
\hline & Balneotherapy & WBE & LBE & \\
\hline & Mean \pm SD & Mean \pm SD & Mean \pm SD & $p$ \\
\hline \multicolumn{5}{|l|}{ ASDAS-CRP } \\
\hline Baseline & $2.8 \pm 0.6$ & $3.1 \pm 0.8$ & $2.8 \pm 0.8$ & 0.352 \\
\hline 4 weeks & $1.8 \pm 0.5^{*}$ & $2.1 \pm 0.8^{*}$ & $1.5 \pm 0.6^{*}$ & $0.022^{* *}$ \\
\hline 12 weeks & $1.8 \pm 0.5^{*}$ & $2.3 \pm 0.5^{*}$ & $1.7 \pm 0.7^{*}$ & $0.001^{* * *}$ \\
\hline \multicolumn{5}{|c|}{ Sclerostin (ng/mL) } \\
\hline Baseline & $6.9 \pm 2.6$ & $9.1 \pm 5.4$ & $7.5 \pm 2.6$ & 0.505 \\
\hline 4 weeks & $6.5 \pm 2.7$ & $8.3 \pm 5.1$ & $8.0 \pm 3.3$ & 0.421 \\
\hline 12 weeks & $7.4 \pm 2.6$ & $9.5 \pm 6.7$ & $8.0 \pm 3.8$ & 0.743 \\
\hline
\end{tabular}

In all groups, SSLs did not differ significantly at 4 and 12 weeks compared to pre-treatment values ( $p>0.05)$. A similar increase in SSL was observed in all groups at 12 weeks of follow-up compared to pre-treatment levels (Table 3).

\section{DISCUSSION}

In this study, significant improvements in disease activity, spine movements, enthesitis score, sleep quality, fatigue, physical function, and QoL were seen in AS patients after balneotherapy, WBE, and LBE interventions, and these effects were maintained at 12 weeks. The patients in the WBE group exhibited a significant improvement in chest expansion at the end of treatment and at 12 weeks of follow-up. Similar, but non-significant increases in SSLs were observed at 12 weeks in all treatment groups.

The Assessment in SpondyloArthritis international Society (ASAS)/European League Against Rheumatism (EULAR) stated that regular exercise and patient education are the cornerstones of non-pharmacological treatment in AS. ${ }^{22}$ The benefits of exercise are not only limited to improvements in physical performance and aerobic capacity, but also positively affect fatigue and mental health. ${ }^{23}$ Exercise programs for AS vary in type, duration, frequency, and intensity. Most studies on exercise in these patients have focused on LBEs. ${ }^{24}$ Land exercises are practiced either at home or in a supervised setting. However, home-based exercises can lead to problems in patient adherence. Therefore, we preferred a supervised group exercise program in this study. As supervised exercise, we randomly assigned both land-based and WBE programs to the patients.

Water-based exercises can be used as an alternative to LBEs in patients with painful musculoskeletal disorders, who can benefit from the effects of buoyancy, viscosity, and water temperature. ${ }^{25,26}$ To the best of our knowledge, the only study comparing land-based and WBEs in patients with AS was conducted by Dundar et al. ${ }^{27}$ In this randomized-controlled study, 69 AS patients were evaluated in terms of pain, spinal movements, disease activity, disability, and QoL. In the home-based land exercise program, the patients were shown the exercises once by a physiotherapist and provided an exercise manual. In the WBE group, similar to our study, the patients were treated in a swimming pool at 32 to $33^{\circ} \mathrm{C}$ with a total of 20 sessions held five days a week for four weeks. The authors reported statistically significant improvements in VAS pain scores, BASDAI, BASFI, BASMI, Short Form-36 scores, and chest expansion in both groups at one month, with all improvements maintained as statistically significant at three months. They also emphasized that the WBE group showed a more remarkable improvement in the QoL and pain scores. ${ }^{27}$ In contrast to their study, we used an AS-specific QoL scale in the present study instead of a generic QoL scale, and both exercise groups showed a statistically similar improvement both immediately after the intervention and at 12 weeks of follow-up. Also, unlike this study, our LBEs were applied in the hospital under the supervision of a physiotherapist, which may have led to an increase in QoL in this group. 
A recent meta-analysis suggested that $\mathrm{WBE}$ resulted in lower BASDAI, but did not provide a significant improvement in BASFI and BASMI scores. ${ }^{28}$ However, in this meta-analysis, both balneotherapy and hydrotherapy studies were evaluated together as water therapy. Therefore, the results should be evaluated carefully. In our study, we found significant improvements in disease activity, physical function, and spinal movement in both exercise groups. Exercises increase plasma levels of endogenous opioids, which provide muscle relaxation and analgesic effects. ${ }^{29}$ The muscle relaxation obtained may also have contributed to the spinal mobility of the patients, and the physical function of the patients may have been improved secondary to this.

Balneotherapy, which has analgesic and myorelaxant effects, can be also a crucial nonpharmacological treatment option in AS patients with pain and paraspinal muscle contractures. ${ }^{8}$ In a recent review evaluating the effectiveness of balneotherapy in rheumatic diseases, the best results of balneotherapy were observed in rheumatic diseases with axial involvement such as AS and enteropathic spondylitis. ${ }^{8}$ In addition, balneotherapy is reported to be safe and is recommended in combination with pharmacological therapy, and a study showed that combined spa/exercise therapy was cost-effective. ${ }^{30}$ Balneotherapy is effective in rheumatic diseases as a result of its mechanical, thermal, chemical, and immunomodulatory effects. ${ }^{31}$ In a non-controlled study conducted by Tishler et al. ${ }^{32}$ with 14 AS patients, patients showed a decrease in morning stiffness and finger-to-floor distance after a two-week balneotherapy program consisting of a spa and a mud bath. In a study by Van Tubergen et al., ${ }^{30}$ 120 AS patients were divided into three groups and given spa treatment in addition to standard drug treatment five days a week for three weeks. The authors reported that the group that received combined exercise with spa treatment showed significant improvements in pain, morning stiffness, activities of daily living scores, BASFI, and BASDAI scores compared to the control group, and that the improvement in activities of daily living lasted up to 40 weeks in the spa-treated group. In our study, we found that a significant improvement was achieved during the study in all variables, except for chest expansion and sclerostin level in the balneotherapy group. Balneotherapy may also have contributed to the analgesic effect by causing an increase in endogenous opioid peptide levels. ${ }^{33}$ Moreover, vasodilation during heat may also increase tissue blood flow and exert an anti-inflammatory effect by removing analgesic metabolites, free radicals, and other pro-inflammatory substances from tissues, resulting in improvements in patients.

Fatigue occurs in more than half of patients with AS and is considered a main symptom of the disease. ${ }^{34}$ Previous studies have reported that exercise reduces fatigue levels in AS. ${ }^{35,36} \mathrm{~A}$ study examining 1,492 spondyloarthritis patients found that fatigue was more common in patients who did not exercise. ${ }^{37}$ Our study demonstrated a statistically significant improvement in FSS immediately post-treatment and at 12 weeks of follow-up in both the WBE and LBE groups. According to data from the literature, exercise may provide improvement in the severity of fatigue secondary to improvement in pain and disease activity. Balneotherapy has also been shown to be beneficial for fatigue in various diseases. ${ }^{38}$ Altan et al. ${ }^{9}$ showed that Nottingham Health Profile fatigue score improved in patients with AS after treatment with three weeks of balneotherapy (30 min once a day), in addition to exercise (home exercise program for 30 min once a day). We also observed a statistically significant improvement in FSS after the intervention and at Week 12 in the balneotherapy group.

Poor sleep quality in patients with AS is associated with the increased disease activity, progressively worsening function, and fatigue. ${ }^{39}$ Therefore, it is beneficial for AS patients to exercise regularly to slow disease progression and improve sleep quality. ${ }^{39}$ Sveaas et al. ${ }^{40}$ reported that controlled high-intensity exercise (three days a week for three months) improved sleep quality in patients with axial spondyloarthritis. Consistent with these literature data, we found that LBE and WBE treatment improved sleep quality in this study. Balneotherapy has also been shown to have positive effects on sleep in various diseases. ${ }^{41}$ In the present study, the balneotherapy group showed improvements in sleep scores both at the end of treatment and at 12 weeks in the intergroup comparisons. In addition, we found that sleep latency improved significantly more in 
the balneotherapy and WBE groups, compared to the LBE group. We believe that favorable results can be obtained in AS patients with sleep disorders by adding exercise and balneotherapy to the current medical treatments.

In the exercise groups in our study, we found a statistically significant improvement in BASDAI and ASDAS-CRP scores after treatment and at 12 weeks. Although we found no significant difference among the groups in BASDAI scores, we found a difference in favor of LBE and balneotherapy in ASDAS-CRP scores. This difference is thought to be due to the difference in CRP change among the groups. Low SSLs in AS patients have been associated with the formation of new syndesmophytes, and sclerostin was reported to be a potential marker of the spine ossification process in these patients. ${ }^{12,42}$ The relationship between exercise and sclerostin was examined in studies designed to measure SSLs immediately after exercise in young or elderly populations, and it was shown that exercise increased sclerostin levels, albeit for a short time. ${ }^{43}$ However, the review of the literature yielded no study investigating the effect of exercise or balneotherapy on SSLs in patients with AS. A study of 30 active AS patients by Saad et al. ${ }^{44}$ showed a progressive increase in SSLs at 6 and 12 months after anti-tumor necrosis factor (TNF) therapy was initiated. It was also found that patients with remarkably persistent inflammation had lower initial SSLs than other patients $(p=0.023)$ and that AS patients with lower SSLs were at a higher risk of having elevated CRP at after 12 months of anti-TNF treatment. The authors suggested that persistent inflammation in AS patients receiving anti-TNF therapy could be attributable to low SSLs. ${ }^{44}$ In this context, we believe that the increase in SSLs observed in our study at 12 weeks after WBE, balneotherapy, and LBE treatments, although not statistically significant, may be important.

The main limitation of our study is not having a control group receiving medical treatment alone. In addition, performing six-month follow-up evaluations might have allowed us to assess the longer-term consequences of these treatments. However, this study also has some strengths. To the best of our knowledge, this is the first study to compare the effectiveness of balneotherapy, WBE, and LBE in patients with AS. Due to the small number of studies investigating the effectiveness of WBE in AS, we believe that our study makes a valuable contribution to the literature. Our study also presents the first analysis of effects of these treatments on SSLs in patients with AS. In addition, the wide range of variables assessed in this study increases the strength of our findings.

In conclusion, AS patients showed significant improvements in disease activity, spine mobility, enthesitis, sleep quality, fatigue, function, and QoL after four weeks of treatment with balneotherapy, WBE, or LBE. Furthermore, these beneficial effects may last for at least 12 weeks. Further large-scale, long-term, prospective, randomized-controlled studies are needed to confirm these findings.

Ethics Committee Approval: The study protocol was approved by the Afyonkarahisar Health Sciences University Ethics Committee (No: 2019/2). The study was conducted in accordance with the principles of the Declaration of Helsinki.

Patient Consent for Publication: A written informed consent was obtained from each patient.

Data Sharing Statement: The data that support the findings of this study are available from the corresponding author upon reasonable request.

Author Contributions: Study concept, acquisition of data, critical revision: E.B., Ü.D., T.K., B.K., H.Y.

Conflict of Interest: The authors declared no conflicts of interest with respect to the authorship and/or publication of this article.

Funding: This study was supported by the scientific research projects unit of our university with the project number 19.TUS.001.

\section{REFERENCES}

1. Raychaudhuri SP, Deodhar A. The classification and diagnostic criteria of ankylosing spondylitis. $\mathrm{J}$ Autoimmun 2014;48-49:128-33.

2. Lories RJ, Haroon N. Bone formation in axial spondyloarthritis. Best Pract Res Clin Rheumatol 2014;28:765-77.

3. Smith JA. Update on ankylosing spondylitis: Current concepts in pathogenesis. Curr Allergy Asthma Rep 2015;15:489.

4. Maguire S, Sengupta R, O'Shea F. The future of axial spondyloathritis treatment. Rheum Dis Clin North Am 2020;46:357-65. 
5. Sharan D, Rajkumar JS. Physiotherapy for ankylosing spondylitis: Systematic review and a proposed rehabilitation protocol. Curr Rheumatol Rev 2017;13:121-5.

6. Millner JR, Barron JS, Beinke KM, Butterworth RH, Chasle BE, Dutton LJ, et al. Exercise for ankylosing spondylitis: An evidence-based consensus statement. Semin Arthritis Rheum 2016;45:411-27.

7. Dagfinrud H, Kvien TK, Hagen KB. Physiotherapy interventions for ankylosing spondylitis. Cochrane Database Syst Rev 2008;2008:CD002822.

8. Cozzi F, Ciprian L, Carrara M, Galozzi P, Zanatta E, Scanu A, et al. Balneotherapy in chronic inflammatory rheumatic diseases-a narrative review. Int J Biometeorol 2018;62:2065-71.

9. Altan L, Bingöl U, Aslan M, Yurtkuran M. The effect of balneotherapy on patients with ankylosing spondylitis. Scand J Rheumatol 2006;35:283-9.

10. Tsui FW, Tsui HW, Las Heras F, Pritzker KP, Inman RD. Serum levels of novel noggin and sclerostinimmune complexes are elevated in ankylosing spondylitis. Ann Rheum Dis 2014;73:1873-9.

11. Ueland T, Stilgren L, Bollerslev J. Bone matrix levels of Dickkopf and sclerostin are positively correlated with bone mass and strength in postmenopausal osteoporosis. Int J Mol Sci 2019;20:2896.

12. Appel H, Ruiz-Heiland G, Listing J, Zwerina J, Herrmann M, Mueller R, et al. Altered skeletal expression of sclerostin and its link to radiographic progression in ankylosing spondylitis. Arthritis Rheum 2009;60:3257-62.

13. Hsieh LF, Wei JC, Lee HY, Chuang CC, Jiang JS, Chang KC. Aerobic capacity and its correlates in patients with ankylosing spondylitis. Int $\mathrm{J}$ Rheum Dis 2016;19:490-9.

14. Calin A, Garrett S, Whitelock H, Kennedy LG, O'Hea J, Mallorie P, et al. A new approach to defining functional ability in ankylosing spondylitis: The development of the Bath Ankylosing Spondylitis Functional Index. J Rheumatol 1994;21:2281-5.

15. Jenkinson TR, Mallorie PA, Whitelock HC, Kennedy LG, Garrett SL, Calin A. Defining spinal mobility in ankylosing spondylitis (AS). The Bath AS Metrology Index. J Rheumatol 1994;21:1694-8.

16. Heuft-Dorenbosch L, Spoorenberg A, van Tubergen $\mathrm{A}$, Landewé $\mathrm{R}$, van ver Tempel $\mathrm{H}$, Mielants $\mathrm{H}$, et al. Assessment of enthesitis in ankylosing spondylitis. Ann Rheum Dis 2003;62:127-32.

17. Durmus B, Altay Z, Baysal O, Ersoy Y, Hacievliyagil SS, Baysal T, et al. Ankilozan spondilitli hastalarda yas ve cinsiyete gore duzeltilmis gogus ekspansiyonunun klinik pratikte kullanimi. Türk Fiz Tip Rehab Derg 2011;57:128-33.

18. Duruöz MT, Doward L, Turan Y, Cerrahoglu L, Yurtkuran M, Calis M, et al. Translation and validation of the Turkish version of the Ankylosing Spondylitis Quality of Life (ASQOL) questionnaire. Rheumatol Int 2013;33:2717-22.
19. Brophy S, Davies H, Dennis MS, Cooksey R, Husain MJ, Irvine $\mathrm{E}$, et al. Fatigue in ankylosing spondylitis: Treatment should focus on pain management. Semin Arthritis Rheum 2013;42:361-7.

20. Buysse DJ, Reynolds CF 3rd, Monk TH, Berman SR, Kupfer DJ. The Pittsburgh Sleep Quality Index: A new instrument for psychiatric practice and research. Psychiatry Res 1989;28:193-213.

21. Machado P, Navarro-Compán V, Landewé $R$, van Gaalen FA, Roux C, van der Heijde D. Calculating the ankylosing spondylitis disease activity score if the conventional c-reactive protein level is below the limit of detection or if high-sensitivity c-reactive protein is used: An analysis in the DESIR cohort. Arthritis Rheumatol 2015;67:408-13.

22. Ward MM, Deodhar A, Gensler LS, Dubreuil M, Yu D, Khan MA, et al. 2019 Update of the American College of Rheumatology/Spondylitis Association of America/Spondyloarthritis Research and Treatment Network Recommendations for the treatment of ankylosing spondylitis and nonradiographic axial spondyloarthritis. Arthritis Rheumatol 2019;71:1599-613.

23. Grazio S, Grubišić F, Brnić V. Rehabilitation of patients with spondyloarthritis: A narrative review. Med Glas (Zenica) 2019;16:144-56.

24. van der Heijde D, Ramiro S, Landewé R, Baraliakos X, Van den Bosch F, Sepriano A, et al. 2016 update of the ASAS-EULAR management recommendations for axial spondyloarthritis. Ann Rheum Dis 2017;76:978-91.

25. Hall J, Swinkels A, Briddon J, McCabe CS. Does aquatic exercise relieve pain in adults with neurologic or musculoskeletal disease? A systematic review and meta-analysis of randomized controlled trials. Arch Phys Med Rehabil 2008;89:873-83.

26. Bender T, Karagülle Z, Bálint GP, Gutenbrunner C, Bálint PV, Sukenik S. Hydrotherapy, balneotherapy, and spa treatment in pain management. Rheumatol Int 2005;25:220-4.

27. Dundar U, Solak O, Toktas H, Demirdal US, Subasi $\mathrm{V}$, Kavuncu $\mathrm{V}$, et al. Effect of aquatic exercise on ankylosing spondylitis: A randomized controlled trial. Rheumatol Int 2014;34:1505-11.

28. Liang Z, Fu C, Zhang Q, Xiong F, Peng L, Chen L, et al. Effects of water therapy on disease activity, functional capacity, spinal mobility and severity of pain in patients with ankylosing spondylitis: A systematic review and meta-analysis. Disabil Rehabil 2021;43:895-902.

29. Anderson E, Shivakumar G. Effects of exercise and physical activity on anxiety. Front Psychiatry 2013;4:27.

30. Van Tubergen A, Boonen A, Landewé R, Rutten-Van Mölken M, Van Der Heijde D, Hidding A, et al. Cost effectiveness of combined spa-exercise therapy in ankylosing spondylitis: A randomized controlled trial. Arthritis Rheum 2002;47:459-67. 
31. Nasermoaddeli A, Kagamimori S. Balneotherapy in medicine: A review. Environ Health Prev Med 2005; 10:171-9.

32. Tishler M, Brostouski Y, Yaron M. Effect of spa therapy in Tiberias on patients with ankylosing spondylitis. Clin Rheumatol 1995;14:21-5.

33. Fioravanti A, Iacoponi F, Bellisai B, Cantarini L, Galeazzi M. Short- and long-term effects of spa therapy in knee osteoarthritis. Am J Phys Med Rehabil 2010;89:125-32.

34. Aissaoui N, Rostom S, Hakkou J, Berrada Ghziouel K, Bahiri R, Abouqal R, et al. Fatigue in patients with ankylosing spondylitis: Prevalence and relationships with disease-specific variables, psychological status, and sleep disturbance. Rheumatol Int 2012;32:2117-24.

35. Masiero S, Poli P, Bonaldo L, Pigatto M, Ramonda R, Lubrano E, Punzi L, Maffulli N. Supervised training and home-based rehabilitation in patients with stabilized ankylosing spondylitis on TNF inhibitor treatment: A controlled clinical trial with a 12-month follow-up. Clin Rehabil 2014;28:56272.

36. Durmus D, Alayli G, Cil E, Canturk F. Effects of a home-based exercise program on quality of life, fatigue, and depression in patients with ankylosing spondylitis. Rheumatol Int 2009;29:673-7.

37. Bianchi WA, Elias FR, Carneiro S, Bortoluzzo $\mathrm{AB}$, Gonçalves CR, da Silva JA, et al. Assessment of fatigue in a large series of 1492 Brazilian patients with Spondyloarthritis. Mod Rheumatol 2014;24:980-4.
38. Koçyiğit BF, Gür A, Altındağ Ö, Akyol A, Gürsoy S. Comparison of education and balneotherapy efficacy in patients with fibromyalgia syndrome: A randomized, controlled clinical study. Agri 2016;28:72-8.

39. Nie A, Wang C, Song Y, Xie X, Yang H, Chen H. Prevalence and factors associated with disturbed sleep in outpatients with ankylosing spondylitis. Clin Rheumatol 2018;37:2161-8.

40. Sveaas SH, Bilberg A, Berg IJ, Provan SA, Rollefstad $S$, Semb AG, et al. High intensity exercise for 3 months reduces disease activity in axial spondyloarthritis (axSpA): A multicentre randomised trial of 100 patients. Br J Sports Med 2020;54:292-7.

41. Koçak FA, Kurt EE, Milletli Sezgin F, Şaş S, Tuncay F, Erdem HR. The effect of balneotherapy on body mass index, adipokine levels, sleep disturbances, and quality of life of women with morbid obesity. Int $\mathrm{J}$ Biometeorol 2020;64:1463-72.

42. Sun W, Tian L, Jiang L, Zhang S, Zhou M, Zhu J, et al. Sclerostin rather than Dickkopf-1 is associated with mSASSS but not with disease activity score in patients with ankylosing spondylitis. Clin Rheumatol 2019;38:989-95.

43. Pickering ME, Simon M, Sornay-Rendu E, Chikh K, Carlier MC, Raby AL, et al. Serum sclerostin increases after acute physical activity. Calcif Tissue Int 2017;101:170-3.

44. Saad CG, Ribeiro AC, Moraes JC, Takayama L, Goncalves CR, Rodrigues MB, et al. Low sclerostin levels: A predictive marker of persistent inflammation in ankylosing spondylitis during anti-tumor necrosis factor therapy? Arthritis Res Ther 2012;14:R216. 